\title{
A case study of the effect of cardiovascular training on cerebral palsy
}

\author{
Estudo do condicionamento cardiovascular na \\ paralisia cerebral - um estudo de caso
}

\section{Jéssica Silva Teixeira, Luiza Mayara Lima de Jesus Santos, Nayhara Lemos dos Santos, Carla Cristine Cunha Casali, Carolina Marques Carvalho Mitre Chaves*}

Universidade de Itaúna (UI), Itaúna, MG, Brazil

Abstract

\begin{abstract}
Introduction: Cerebral palsy (CP) is a non-progressive disorder characterized by changes in muscle tone and voluntary movement, leading to adaptive changes in muscle length and in some cases, resulting in bone deformities and increased energy expenditure while performing activities of daily living. Objective: The aim of this study was to investigate the effects of cardiovascular training by an adult with athetoid CP. Methods: The sample was composed of one patient with athetoid CP. The instruments used were the timed ten-meter walk test; the SF-36 quality of life questionnaire, a six-minute walk test and the Timed Up and Go test. Using an exercise bike and resistance exercises for the upper limbs, the patient underwent 24 sessions lasting fifty minutes each during eight weeks. Results: In all tests, significant improvement was observed at four and eight weeks, especially in the first four, and progressed in the following four weeks. In the post-training period, improvement was observed when compared to pre-training values. The SF-36 questionnaire on quality of life showed increase in some areas and decrease in others. Conclusion: Patients with CP can benefit from a physical training program, which can improve their quality of life and be included in their rehabilitation protocol.
\end{abstract}

Keywords: Cerebral Palsy. Training. Aerobic Exercise. Adult.

\footnotetext{
*JST: undergrad, e-mail: jessicast11@hotmail.com

LMLJS: undergrad, luizalimajs@hotmail.com

NLS: undergrad, nahyaralemos@hotmail.com

CCCC: MS, e-mail: ccccasali@yahoo.com.br

CMCMC: MS, e-mail: carolinamchaves@uol.com.br
} 


\section{Resumo}

Introdução: A Paralisia Cerebral (PC) é um distúrbio não progressivo que caracteriza-se por alterações no tônus muscular e movimentação voluntária, levando a modificações adaptativas do comprimento muscular e em alguns casos, chegando a resultar em deformidades ósseas e aumento do gasto energético durante a realização de atividades da vida diária. Objetivo: Avaliar os efeitos do condicionamento cardiovascular em um adulto com PC atetóide. Métodos: Participou do estudo um paciente com quadriparesia atetóide. Como instrumentos foram utilizados o Teste de Dez metros; o Questionário de Qualidade de Vida SF-36, o Teste de Caminhada de 6 Minutos e Teste Timed Get Up and Go. Foram realizadas 24 sessões, com duração de cinquenta minutos, durante oito semanas, utilizando uma Bicicleta ergométrica e exercícios resistido de MMSS. Resultados: Em todos os testes aplicados foi possível observar melhora após a quarta e a oitava semanas, especialmente nas primeiras quatro semanas. No destreino, observou-se melhora quando comparado com os valores de prétreinamento. O Questionário de Qualidade de Vida SF-36 apresentou melhora em alguns domínios e declínio em outros. Conclusão: Um paciente com PC pode se beneficiar de um programa de condicionamento, podendo este melhorar sua qualidade de vida, e ser incluído em seu protocolo de reabilitação.

Palavras-chave: Paralisia Cerebral. Condicionamento. Exercício Aeróbico. Adulto.

\section{Introduction}

Cerebral palsy (CP) is a group of permanent postural and movement development disorders that limit activities, and are attributed to a non-progressive disorder that occurs during fetal development of the brain or childhood (1). Studies have shown the increased prospect of life of these patients when they do not present significant pathologies and receive appropriate medical care $(2,3)$.

The clinical manifestations of CP most commonly observed are: changes in posture and balance (4), muscle tone (5), spasticity (6), muscle weakness (7) and low resistance to physical activity. These changes result in lack of control over movements, leading to adaptive changes of muscle length, and in some cases can result in bone deformities (8).

The low resistance to physical activity observed in these individuals can be attributed to reduced oxidative capacity of the paretic muscles, overall decrease of aerobic resistance, and recruitment of motor units with increased energy expenditure during activities of daily living and sub-maximal exercise (9). The combination of these factors can lead to functional and social losses, and these patients tend to become increasingly sedentary (10).

According to Batista et al. (10), patients with CP benefit from aerobic training, which should be included in rehabilitation programs. Gains in functional ability were observed in CP patients in aerobic conditioning programs, with less energy expenditure in activities of daily living (ADL) and reduced cardiovascular risk, with benefits in control of blood pressure (BP) and improvement in maximal oxygen consumption (VO2 max).

Rizetti et al. (11) investigated the effects of muscle strengthening on walking in adolescents with diplegic spastic $\mathrm{CP}$, and verified improvements in muscle strength and functional capacity in walking.

In addition, individuals with $\mathrm{CP}$ are possibly physically unfit, and therefore performance of a fitness program is hampered due to their physical limitations from motor incoordination. Studies show that children with $\mathrm{CP}$ present changes in autonomic postural adjustments that directly influence heart rate (12). Such changes associated with other comorbidities from the kineticfunctional clinical picture of an individual with CP suggest functional loss and premature aging in adult patients (13). Given the lack of studies that include aerobic training in the rehabilitation protocol for adults with $\mathrm{CP}$, the aim of this study was to evaluate the feasibility and effects of cardiovascular training on an adult with CP.

\section{Methods}

This study was submitted to the Human Research Ethics Committee, and received opinion number 867.273. Participants' prior authorization was requested and granted through signature of a free and informed consent form.

This was a case study carried out in the Comprehensive Physical Therapy Clinics of the University of Itaúna, in the southeastern Brazilian 
state of Minas Gerais. One adult male participated in the study, who was 35 years old and had a clinical diagnosis of athetoid CP. The participant had no cognitive deficit, and was graduated in computer science. At the time the study was carried out, the participant worked in the IT department of the university, a holder of political office, and required the aid of caregivers to perform activities of daily living, including personal hygiene and feeding. This man was accustomed to practicing physical activity on the weekends, for example, he played the position of goalkeeper in soccer. The participant had a scissor gait and used the aid of a walker adapted with front wheels. The participant's motor dysfunctions included: quadriplegia; floating tone with involuntary movements; tonic reflexes that dominated posture and interfered with postural alignment; motor incoordination and postural changes such as: pronated feet, valgus and semiflexed knees, hips adduction with internal rotation and kyphoscoliosis. The patient did not present cardiovascular diseases, and complained of fatigue during the practice of activities of daily living, especially those involving associated movements of upper and lower limbs.

\section{Experimental Design}

The evaluations were carried out in four stages during the study: before the start of training, during training (four weeks), at the end of the eight-week training, and thirty days later, the retention period (10).

Initially, anamnesis was performed to collect personal data, anthropometric measurements and postural changes.

The participant was classified according to the Gross Motor Function Classification System (GMFCS), which assessed his level of motor impairment related to sitting and walking, and starting voluntary movement. The GMFCS is divided into five levels, and the higher the score, the greater the motor impairment (14).

The evaluation criteria selected for the present study were: walking speed, functional capacity, quality of life, mobility and balance. The tools used for these criteria were: the 10-meter walk test (TM10), the six-minute walk test (SMWT), the Borg scale, the abbreviated version of the SF-36 quality of life questionnaire (SF-36), and the Timed Up and Go test (TUG), all duly validated, easy to apply and feasible for clinical practice.

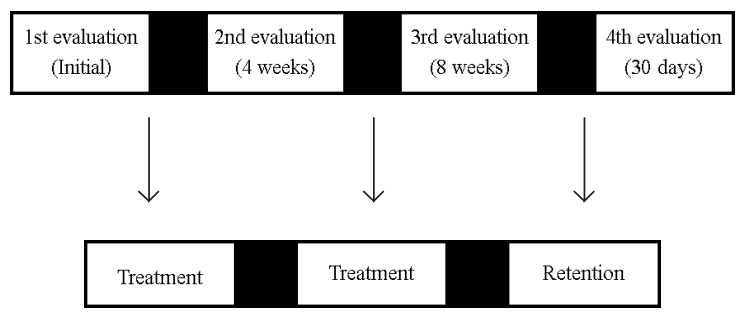

Figure 1 - Flowchart of the care protocol proposed in the study.

In addition to quantitative testing, qualitative descriptive analysis was performed by means of notes from the reports that the patient kept during the course of training, in order to check possible positive factors or even problems that could occur during this phase.

The blood pressure of the patient was monitored at the beginning and end of each procedure in all assessments and treatment sessions.

\section{Evaluation of functional capacity}

The SMWT was applied. This test is simple, secure, and enables a comprehensive and integrated response of all systems involved during the exercise, based on the distance traveled in six minutes. The SMWT has a submaximal level, and because most activities of daily living are performed at submaximal levels, it is an optimal way to evaluate physical capacity. The following equation is currently used to measure the total distance traveled (TDT) (15):

TDT6pred $=356.658-(2.303 \mathrm{x}$ age $)+(36.648 \mathrm{x}$ gender $)+(1.704 \times$ height $)+(1.365 \times$ HR variation $)$

\section{Assessment of walking speed}

The TM-10 was used to measure walking speed, in which the participant was asked to walk at a comfortable speed, wearing his own shoes, for a distance of 14 meters. The first and last two meters were disregarded, and the time to travel 10 meters was timed (16).

\section{Evaluation of balance and functional mobility}

The Timed Up and Go test (TUG) was used to measure the time (seconds) spent by the participant to 
get out of a standard armchair (height approx. 46 $\mathrm{cm}$ ), walk a distance of three meters, turn around, go back to the chair and sit down again (17).

\section{Evaluation of quality of life}

The abbreviated version of the SF-36 questionnaire on quality of life was applied by three undergraduate physical therapy students. In this test, the patient was aided when prompted, without interference in their responses. The questionnaire is made up of 36 items grouped into eight domains: functional capacity, physical aspects, pain, general health, vitality, as well as social, emotional and mental health aspects. The final score ranged from 0 to 100 , and the lower the score, the worse the general state of health (18).

Level of dyspnea and fatigue in the lower limbs was measured by the modified Borg scale, a subjective, self-reporting test that consists of a score from 0 to 10 , where 0 represents no effort and 10 represents maximum effort (19).

\section{Rehabilitation protocol}

After the initial evaluation, the participant began a conditioning program that consisted of initial 15 minutes (20) of proprioceptive neuromuscular facilitation resistance exercises (PNF) of the upper limbs, 20 minutes of bike exercise (due to difficulty of the patient to walk for prolonged time, with consequent involuntary movement, and therefore not choosing the treadmill) and 15 minutes of stretching of the ischiotibial and adductor muscles.

The aerobic exercise program started with moderate intensity levels of maximum heart rate (40 - 50\%), and progressed to higher levels (50 - 80\%). The heart rate was checked at three times before, during and after the training session (21). In all sessions, the modified Borg scale was used to observe the participant's level of fatigue.

Some adaptations were necessary for application of the training protocol, such as: use of four tracks to stabilize and position the lower limbs properly on the bike, with two tied at the feet of the participant and the other two around the knees (Figure 1a), the latter with the aid of two therapists to lead the movement and avoid hip adduction (Figure 1b).
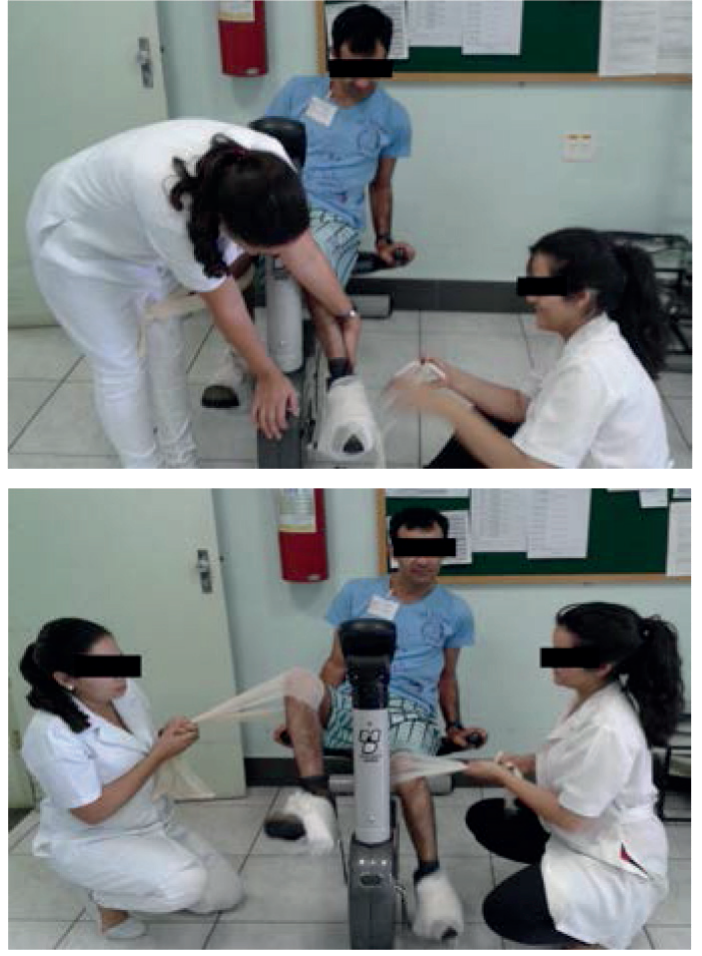

Figure la - Adaptation of the track at the foot of the participant. Figure $\mathbf{l b}$ - Bandages were placed around the kneesto avoid hip adduction and internal rotation during the exercise.

The first session of the training program was disregarded in order familiarize the patient with the proposed protocol (10).

The cardio-respiratory training program was done on a horizontal ergometric exercise bike (Movement Brudden Perform H3, Brazil).

Patient reports were collected throughout the training protocol, and recorded in a logbook.

The treatment protocol totaled 24 sessions lasting approximately 50 minutes each, three times per week on alternate days (10).

The fourth evaluation was performed 30 days after the last session, in order to assess the participant in the post-training period. He did not carry out any kind of physical activity in addition to activities of daily living (22) during the study.

\section{Results}

The participant was classified at level III of the GMFCS, which corresponds to walking with the aid of equipment, with limitations in gait and in the community. 
The values found in the four evaluations for distance walked on the SMWT were 154 meters (47.2\%); 170 meters (52.1\%), 173 meters (53.6\%) and 162 meters (49.6\%), respectively, considering the expected distance of 326 meters. A significant improvement was found in the first four weeks, which fell to a lower rate in the following four weeks. In the post-training evaluation, a decline was observed, but remained improved when compared with the pre-training values (Figure 2).

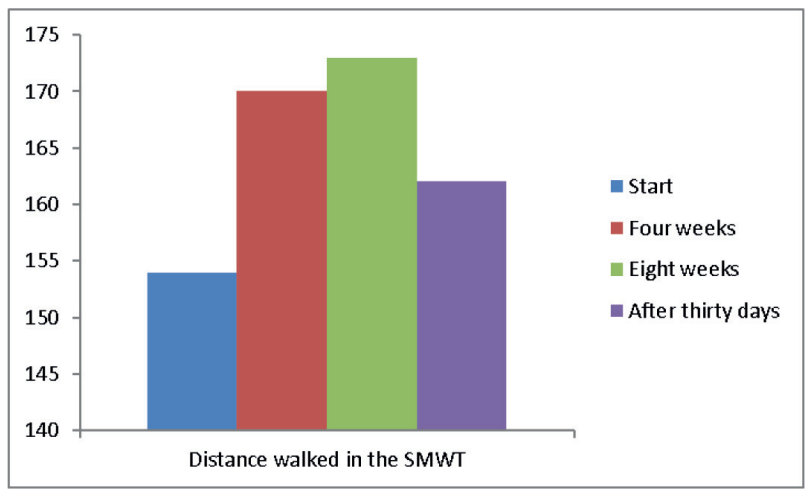

Figure 2 - Values for distance walked in the six-minute walk test.

The values found in the TUG test were 38 seconds, 30.3 seconds, 24.3 seconds and 30 seconds, respectively, showing a gradual improvement during the eight weeks of training (Figure 3). The TM-10 values found were 28.6 seconds; 21.3 seconds; 17.3 seconds and 26.3 seconds, respectively. A clear improvement was also observed in the first four weeks compared to the second four weeks. In the post-training analysis, 30 days after the treatment was complete, both tests showed a decline, though maintained better values than the pre-treatment (Figure 3).

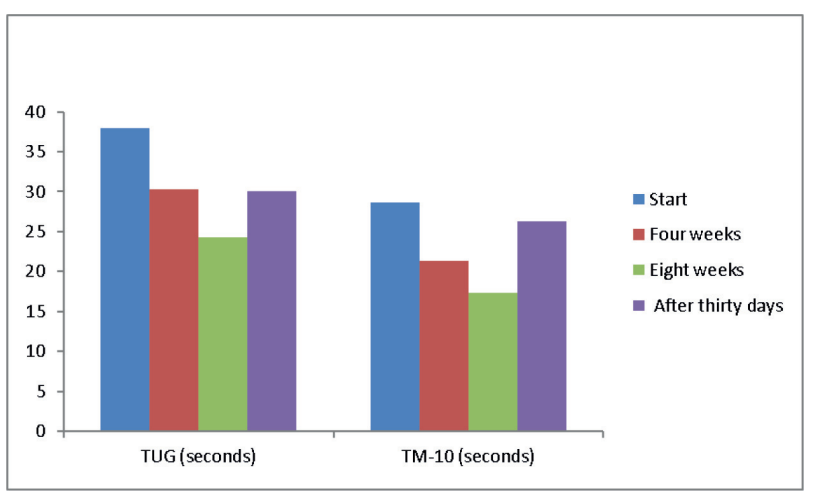

Figure 3 - Values found in the TUG and TM-10 tests in relation to the variable time (seconds).
The results of the scores of each domain of the SF-36 are shown in Figure 4. In regard to the domain functional capacity, an improvement was observed in the first four weeks along with a slight decline at the end of eight weeks, returning to pre-treatment values. The values found in the post-training analysis were lower than pre-training values.

Analysis of the pain domain showed a gradual improvement in all the evaluations, being the most significant in post-training. The vitality domain showed a decline in all evaluations. On the other hand, the domains general state of health, emotional and mental health aspects maintained significant values during all evaluations, and the latter increased in the posttraining evaluation.

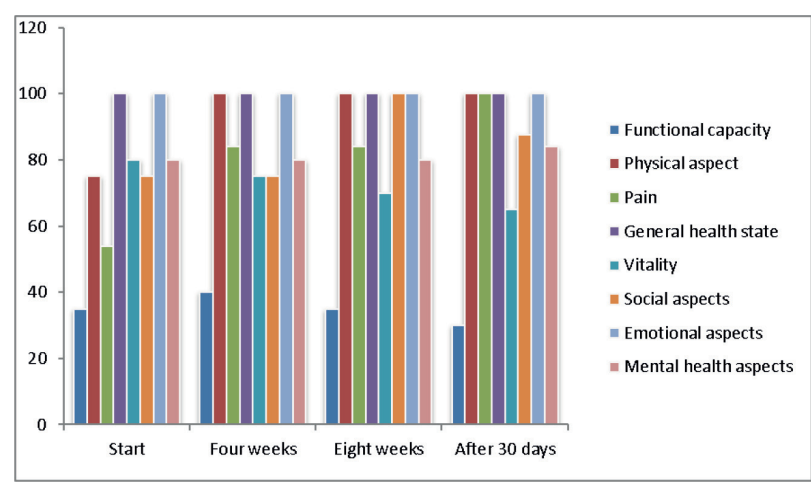

Figure 4 - Scores of each domain of the SF-36 quality of life questionnaire.

\section{Daily report}

In the information collected, there were reports of pain in the left lower limb on the anterior region of the thigh, and this complaint was absent during the course of treatment. In the second evaluation, after four weeks of training, the patient reported improved walking and reduced fatigue:

"I'm feeling improvement in walking, because my knees are not knocking and my fatigue decreased".

In the seventh session the patient showed lower performance during the aerobic exercise, and reported not having slept well the night before. In the session prior to the third evaluation, the patient had lower performance during aerobic exercise, and when questioned by the researchers, reported feeling anxious due to personal issues. 
In most of the sessions, the patient did not report pain, discomfort or fatigue, demonstrating good adaptation to the treatment.

\section{Discussion}

The hypothesis that a patient with athetoid CP could benefit from a program of cardiovascular fitness, and the viability of this intervention, was accepted in this study, since this can be a resource to improve the functionality and quality of life of these patients. In the present study, there was an obvious improvement in distance walked on the SMWT, TUG and TM-10 tests during the first four weeks, with gradual evolution but in smaller proportions. In the post-training evaluation, the patient presented a decline when compared to the period of training, yet maintained the best initial values.

According to the results, a training program consisting of twenty-four sessions was effective in improving cardiovascular fitness. Batista et al. (10), when conducting a study with children and adolescents with CP for 24 sessions, found reduced blood pressure and positive effects on cardiorespiratory fitness. In the present study, the variable blood pressure was measured but not studied, because it was not identified as being associated with the primary purpose of the study, and also because the patient always showed values within the normal range.

In the analysis of the results, it was observed that in the first four weeks, improvement of functional capacity was higher in relation to the following weeks. This finding can be explained by the fact that the participant was sedentary, because exercise triggers a physiological stress to the organism as a result of the great increase in energy demand compared to being at rest. Consequently, the regular practice of exercise promotes morphological and functional adaptations that require an increase in their intensity to obtain more significant gains (23).

Recent studies that analyzed sedentary behavior in cerebral palsy suggest that sedentary behavior parameters developed for people with normal motor skills should not be considered in cerebral palsy $(24,25)$. According to Verschuren, the physiological mechanisms, postures and levels of energy expenditure representing sedentary behavior in cerebral palsy can be very different from those of the general population (25), suggesting the importance of undertaking studies on this population.

In the SMWT, a gain was observed in the distance traveled, which suggested the relevance of these results given the musculoskeletal changes present in the patient, such as floating, motor incoordination, dystonia, muscle weakness and fatigue (26). In addition to the physiological benefits provided by aerobic training, such as lowered blood pressure, improved sensory-motor function, aerobic capacity and maximal oxygen consumption (27).

The gradual improvement of the values found in the TM-10 and TUG tests can result in improvement of walking speed, balance and functional mobility, which corroborates the findings by Silva and Daltrário (28), who, when carrying out walking training on a treadmill with an individual with CP, noted significant functional gains with regard to mobility, which caused major impact on their daily routine.

Paiva et al. (29), when reviewing the benefits of physical exercise in children and adolescents with cerebral palsy, concluded that the reports were concentrated on improvement in walking variables, such as speed and cadence, as well as improvement in lower limb muscle strength and aerobic capacity, providing better mobility and function, and resulting in the higher participation of this population in society. In the present study, it was seen that the patient obtained improvement in walking speed, mobility and functional capacity.

Post-training in patients with cerebral palsy is little studied. In this study it was seen that after 30 days of the end of treatment, the values found were better than the pre-treatment, findings, which resemble those of Darrah et al. (30), who, when applying an aerobic training program in cycling and muscle strengthening in adolescents with $\mathrm{CP}$, noticed that the improvements were maintained at ten weeks after finishing the program. A similar behavior was observed in individuals without CP. Michelin et al. (22), when assessing the effect of one month of posttraining on physical fitness of 44 individuals, concluded that at the end of their treatment protocol, the strength gains of the lower limbs and aerobic capacity were maintained, with only loss in flexibility.

According to Christofoletti et al. (31), quality of life can be described as the perception of the individual with regard to their personal, social and cultural lives, and may be altered by intrinsic and extrinsic factors. In this study, by analyzing the values found in the 
SF-36 questionnaire, there was improvement in the domains of pain, social and physical aspects.

There were declines that were possibly influenced by extrinsic factors, unrelated to the study, which can be explained by the information collected in the log report that reflected negatively on these results. Among them vitality is highlighted, which showed a decline in all evaluations, being contradictory to the domains of general state of health, physical and emotional aspects and mental health, which had positive values in the results. The scale on vitality includes levels of energy and fatigue (32), and involves physical and mental components. In this context, the decreased vitality score may have been due to the influence of personal factors associated with physical fatigue of the patient. For Nunes (33), quality of life questionnaires address the vision of the patient and the impact that the disease causes on their daily life, which shows the relevance of this information and the need for more studies on the subject.

The patient's report that after four weeks, "I feel improvement in walking, because my knees are not knocking and my fatigue decreased", demonstrates subjective improvement in quality of life, which corroborates the findings of Noce et al. (34), who verified the effects of physical activity on quality of life of people with physical disabilities, and concluded that regular exercise seems to have a positive effect on perceived high level of quality of life.

Given the scarcity of studies that evaluate the effectiveness of aerobic training in this population, it is necessary to encourage the development of research on the subject. Slot et al. (35) reported that this population presents cardiovascular risk factors such as hypertension and high total cholesterol, which suggests the importance of therapists to be more concerned with cardiovascular dysfunction, and not the commonly tested and treated dysfunctions such as strength, posture, balance and ADL, including aerobic exercise in their treatment protocol.

During the study there were no complications that prevented application of the treatment protocol, or damaged the physical and mental integrity of the participant.

\section{Conclusion}

The protocol studied proved to be safe and effective for a patient with athetoid CP. It can be concluded that eight weeks of training caused gains in functional capacity, mobility and walking speed, with these gains being most obvious in the first four weeks, possibly due to the sedentary condition of the participant. Such information suggests that a patient with CP may benefit from a conditioning program, which can improve their quality of life.

When looking at the post-training period, a decline was verified in all areas measured, showing that four weeks without training caused regression in the parameters evaluated. Therefore, it is suggested that an aerobic program should be included in the rehabilitation protocol of these patients, and the non-activity period should not be extended.

Given this and the scarcity of literature on the subject, further research should be developed with a larger number of participants, in order to better clarify and emphasize the benefits of the conditioning program.

\section{References}

1. Prado MTA, Fell RF, Silva RCR, Pacagnelli FL, Freitas SBZ, Janial AEM, et al. Motor function and quality of life of individuals with cerebral palsy. ABCS Health Sci. 2013;38(2):63-7.

2. Strauss D, Brooks J, Rosenbloom L, Shavelle R. Life expectancy in cerebral palsy: an update. Dev Med Child Neurol. 2008;50(7):487-93.

3. Donkervoort M, Roebroeck M, Wiegerink D, van der Heijden-Maessen H, Stam H. Transition Research Group South West Netherlands. Determinants of functioning of adolescents and young adults with cerebral palsy. Disabil Rehabil. 2007;29(6):453-63.

4. Maciel F, Mazzitelli C, Sá CSC. Postura e Equilíbrio em Crianças com Paralisia Cerebral Submetidas a Distintas Abordagens Terapêuticas. Rev Neurocienc. 2013;21(1):14-21.

5. Souza Kes, Sandako AN, Carvalho SMR, Braccialli LMP. Classificação do grau de comprometimento motor e do índice de massa corpórea em crianças com paralisia cerebral. Rev Bras Cresc e Desenv Hum. 2011;21(1):11-20.

6. Ranatunga KW. Skeletal muscle stiffness and contracture in children with spastic cerebral palsy. J Physiol. 2011:589(Pt 11):2665. 
7. Mockford M, Caulton JM. The Pathophysiological functions Basis of Weakness in Children With Cerebral Palsy. Pediatr Phys Ther. 2010;22(2):222-33.

8. Rothstein JR, Beltrame TS. Características motoras e biopsicossociais de crianças com paralisia cerebral. Rev Bras Cienc Nov. 2013;21(3):118-26.

9. Teixeira-Salmela LF, Oliveira ESG, Santana EGS, Resende GP. Fortalecimento muscular e condicionamento físico em hemiplégicos. Acta Fisiatrica. 2000;7(3):108-18.

10. Batista KG, Lee PO, Serradilha SM, Souza GAF, Bella GP, Souza RCT. Cardiorrespiratório conditioning benefits in children or adolescents with cerebral palsy. Fisioter Mov. 2010;23(2):201-9.

11. Rizetti DA, Fabbrin APA, Trevisan CM. Efeitos do fortalecimento muscular na marcha de adolescentes portadores de paralisia cerebral espástica diplégica. Arq Cienc Saude. 2011;15(2):181-7.

12. Cunha AB, Zamunér AR, Moreno MA, Tudella E, Silva E. Variabilidade da frequência cardíaca em crianças com paralisia cerebral. Fisioter Neuroped. 2011;163-78.

13. Margre ALM, Reis MGL, Morais RLS, Ramos AD. Adultos com a parilisia cerebral: implicações para intervenção em neuropediatria. Fisioter Neuroped. 2011;305-20.

14. Hanna SE, Rosenbaum PL, Bartlett DJ, Palisano RJ, Walter SD, Avery L, et al. Stability and decline in Gross motor function among children and youth with cerebral palsy aged 2 to 21 years. Dev Med Child Neurol. 2009;51(4):295-302.

15. Britto RR, Probst VS, Andrade AF, Samora GA, Hernandes NA, Marinho PE, et al. Reference equations for the six-minute walk distance based on the Brazilian multicenter study. Braz J Phys Ther. 2013;17(6):556-63.

16. Ovando AC, Michaelsen SM, Carvalho T, Herber V. Cardiopulmonary fitness Evaluation in patients with Hemiparesis after Stroke. Arq Bras Cardiol. 2011;96(2):140-7.

17. Nicollini-Panisson RD, Donadio MV. Timed "Up \& Go" test in children and adolescents. Rev Paul Pediatr. 2013;31(3):377-83.
18. Cesário CMM, Penasso P, Oliveira APR. Impacto da disfunção motora na qualidade de vida em pacientes com Acidente Vascular Encefálico. Rev Neurocienc. 2006;14(1):6-9.

19. Cavallazzi TGL, Cavallazzi RS, Cavalcante TMC, Bettencourt ARC, Diccini S. Avaliação do uso da Escala Modificada de Borg na crise asmática. Acta Paul Enferm. 2005;18(1):39-45.

20. Dutton M. Fisioterapia Orthopedic Physical Therapy: Examination, assessment and intervention. 2. ed. Porto Alegre: New Haven, 2010.

21. Thompson WR. Prescrição do Exercício para Outras Populações Clínicas. In: Thompson WR, Gordon NF, Pescatello LS. Diretrizes do ACSM para os Testes de Esforço e sua Prescrição. 8th ed. Rio de Janeiro: Guanabara Koogan; 2009. p. 152-79.

22. Michelin E, Coelho CDF, Burini RC. Efeito de um mês de destreinamento sobre a aptidão física relacionada saúde em programa de mudança de estilo de vida. Rev Bras Med Esporte. 2008;14(3):192-6.

23. Diretriz de Reabilitação Cardíaca. Arq Bras Cardiol. 2005;84(5):431-40.

24. Innes J, Darrah J. Sedentary behavior: implications for children with cerebral palsy. Pediatr Phys Ther. 2013;25(4):402-8.

25. Verschuren O, Darrah J, Novak I, Ketelaar M, Wiart L. Health-enhancing physical activity in children with cerebral palsy: more of the same is not enough. Phys Ther. 2014;94(2):297-305.

26. Amaral PP, Mazzitelli C. Alterações ortopédicas em crianças com paralisia cerebral da clínica-escola de Fisioterapia da Universidade Metodista de São Paulo. Rev. Neurocienc. 2003;11(1):29-33.

27. Potempa K, Lopez M, Braun LT, Szidon JP, Fogg L, Tincknell T. c1995;26(1):101-5.

28. Silva MS, Daltrário SMB. Cerebral palsy: functional performance after training treadmill gait. Fisioter Mov. 2008;21(3):109-15.

29. Paiva MS, Nardi MG, Streiff TG, Chamlian TR. Benefícios do exercício físico para crianças e adolescentes com paralisia cerebral: uma revisão bibliográfica. Acta Fisiatr. 2010;17(4):175-9. 
30. Darrah J, Wessel J, Nearinburg P, O'Connor M. Evaluation of community fitness program for adolescents with cerebral palsy. Pediatr Phys Ther. 1999;11:18-23.

31. Christofoletti G, Hygashi F, Godoy ALR. Cerebral palsy: an analysis of motor compromising on the quality of life. Fisioter Mov. 2007;20(1):37-44.

32. Ferreira P. A medição do estado de saúde: criação da versão portuguesa do MOS SF-36. Coimbra (Portugal): Universidade de Coimbra - CEISUC; 1998. Portuguese.

33. Nunes LCBG. Tradução e Validação de instrumentos de avaliação motora e de qualidade de vida em paralisia cerebral [dissertation]. Campinas (Brazil): Universidade Estadual de Campinas; 2008. Portuguese.

34. Noce F, Simim MAM, Mello MT. A percepção de qualidade de vida de pessoas portadoras de deficiência física pode ser influenciada pela pratica de atividade física? Rev Bras Med Esporte. 2009;15(3):174-8.

35. van der Slot WM, Roebroeck ME, Nieuwenhuijsen C, Bergen MP, Stam HJ, Burdorf A, et al. Cardiovascular disease risk in adults with spastic bilateral cerebral palsy. J Rehabil Med. 2013;45(9):866-72.

Received in 08/05/2015

Recebido em 05/08/2015

Approved in 11/19/2015

Aprovado em 19/11/2015 
